\title{
Os desafios do turismo no contexto da sustentabilidade: as contribuições do turismo de base comunitária
}

\author{
Andrés Burgos* Frédéric Mertens**
}

\author{
Universidade de Brasília (Brasil)
}

\begin{abstract}
Resumo: A construção de um modelo de desenvolvimento turístico sustentável capaz de gerar benefícios econômicos e sociais, ao mesmo tempo em que minimize os impactos ambientais, exige atenção às questões relacionadas à gestão participativa. Nesse contexto, o turismo de base comunitária se apresenta como uma prática de desenvolvimento turístico capaz de apontar caminhos para a sustentabilidade, desde que enraizada na participação e protagonismo social das populações locais. Este artigo propõe uma discussão teórica acerca dos impasses e perspectivas da gestão participativa no contexto da sustentabilidade turística através da proposta do turismo de base comunitária. Como síntese, evidencia-se a constatação da importância da participação social na atual configuração sistêmica do turismo em que a atividade vem superando a imagem meramente econômica para adquirir novas dimensões, transversalidades e interdependências.
\end{abstract}

Palavras-Chave: turismo; enfoque sistêmico; sustentabilidade; gestão participativa; turismo de base comunitária; participação social.

The challenges of tourism in the context of sustainability: the contributions of community-based tourism

Abstract: The construction of a model of sustainable tourism development able to generate economic and social benefits at the same time minimize the environmental impacts, requires attention to issues related to participatory management. In this context, community-based tourism is presented as a tourism development practice that is able to point out paths to sustainability, provided that it is rooted in the participation and social leadership of local populations. This paper proposes a theoretical discussion about the dilemmas and perspectives of participatory management in the context of sustainable tourism through the proposed of community-based tourism. As a synthesis, it's evidenced the premise of importance of social participation in the current systemic configuration of tourism in which the activity is overcoming the merely economic image to get new dimensions, transversalities and interdependencies.

Key Words: tourism; systemic approach; sustainability; participatory management; community-based tourism; social participation.

\section{Introdução}

$\mathrm{Na}$ esteira do crescimento do turismo no mundo, principalmente a partir da segunda metade do século XX, o conceito de desenvolvimento sustentável vem ganhando destaque nos discursos políticos, acadêmicos e na mídia, sendo incluído na pauta das discussões e dos estudos do turismo (Garrod e Fyall,

Graduação em Ciências Biológicas (Universidade de Santiago de Compostela) e Mestre em Desenvolvimento Sustentável (Universidade de Brasília). Pesquisador do Centro de Desenvolvimento Sustentável da Universidade de Brasília e membro ativo do Laboratório de Estudos em Turismo e Sustentabilidade - LETS/UnB; E-mail: anburgosdelgado@unb.br

* Graduação em Ciências Zoológicas (Université Libre de Bruxeles) e doutorado em Ciências Ambientais (Université du Québec à Montreal). Professor adjunto no Centro de Desenvolvimento Sustentável da Universidade de Brasília; E-mail: fmertens@unb.br 
1998; Swarbrooke, 2000; Dias, 2003; Saarinen, 2006). Fomentar e praticar turismo, de base sustentável, requer um novo olhar sobre os problemas sociais, culturais e ambientais do destino turístico, de modo a refletir sobre os rumos que o turismo deve seguir para promover seu potencial positivo, minimizando seus impactos negativos.

Embora não apareça como um tema central de pesquisa na literatura do turismo, a participação social vem sendo discutida, há algum tempo, como uma necessidade e diferencial no produto turístico, representando uma ferramenta para a conservação e o desenvolvimento local e, portanto, apresentando-se como uma das possíveis soluções à problemática da sustentabilidade (Tosun, 2000; Mowforth e Munt, 2003). Desta forma, para que o paradigma da sustentabilidade turística possa ser traduzido em aplicações práticas que gerem benefícios sociais, econômicos e ambientais, minimizando ou evitando os possíveis efeitos negativos do turismo, são necessários mecanismos de planejamento que permitam às comunidades definir e regular o uso dos seus territórios, controlando a capacidade de carga ambiental, social e cultural, assim como monitorando e avaliando as atividades desenvolvidas.

Diante disso, o turismo de base comunitária (TBC) emerge como uma resposta de resistência às pressões mundiais do mercado turístico que, alem de excluir as populações locais dos potenciais benefícios do turismo, também ameaçam sua coesão social, cultural e seu hábitat natural. Assim, em contraposição ao turismo massificado e enraizado em uma proposta de desenvolvimento socialmente mais justo e ambientalmente responsável, o TBC se consolidou na última década no Brasil como um modelo de desenvolvimento turístico que pode apontar caminhos para a sustentabilidade.

O protagonismo social, mediante a mobilização de recursos próprios e a valorização do patrimônio comum, destaca-se como princípio norteador do turismo de base comunitária (Jones, 2005; Hiwasaky, 2006; Mielke, 2009). A retórica do discurso oficial sobre o TBC contempla o envolvimento dos atores locais através de um processo de participação e organização social, no qual as comunidades assumem um papel ativo no planejamento e gestão da atividade, visando o bem-estar e a geração de benefícios para seus membros. A gestão participativa é entendida aqui como processo e instrumento dinamizador resultante do engajamento de indivíduos em ações coletivas, onde diferentes atores sociais viabilizam um projeto, procurando um objetivo comum, mas mantendo as particularidades de seus lineamentos de ação e interesses pessoais.

Neste sentido, este trabalho visa contribuir com a reflexão teórica sobre como a participação social pode lançar luz à gestão participativa no TBC e à sua relação com o turismo sustentável, atendendo à complexidade que caracteriza ao sistema turístico. $\mathrm{O}$ intuito é apresentar uma abordagem critica acerca da gestão participativa e a sustentabilidade turística através da contribuição do turismo de base comunitária. Para isso, em primeiro lugar é caracterizado o sistema turístico como um fenômeno complexo. Em seguida, apresenta-se o turismo no marco do desenvolvimento sustentável. Então, são discutidos os principais aspectos teórico-conceituais relativos ao turismo de base comunitária e sua correlação com as noções de sustentabilidade. Por fim, com o objetivo de explorar a importância da gestão participativa como peça-chave da sustentabilidade turística, o texto analisa as formas e limites da participação social no TBC.

\section{Turismo como sistema complexo}

A atividade turística vem ganhando importância em todo o mundo em função do seu papel relevante no desenvolvimento econômico e também social. A atual crise financeira não parece ter produzido uma inversão no aumento crescente do peso e da importância relativa que o turismo tem em nível global, uma vez que os indicadores disponíveis apontam para uma notável capacidade de resiliência da atividade turística. Conforme divulgado pela Organização Mundial de Turismo (WTO) e o Banco Mundial (WB), a atividade turística continua sendo uma importante alavanca para a economia, representando uma parte significativa dos empregos e do produto interno bruto (PIB) global. Assim, o turismo envolve 9\% do PIB e 9,09\% do emprego mundial. Além disso, o mercado de viagem representa $6 \%$ das exportações mundiais totais (UNWTO, 2014). Como categoria de exportação, o turismo se situa ademais no $4^{0}$ lugar, depois apenas dos combustíveis, produtos químicos e automóveis (WB, 2012).

No início do século XX o turismo se converteu na atividade econômica mais importante do mundo, registrando um crescimento espetacular. Entre os anos 1950 e 2000, o fluxo internacional de turistas passou de 25 a 682 milhões, representando uma taxa de crescimento anual perto de 5\% (WTO, 2010). Já entre 2000 e 2008, as viagens internacionais cresceram 4,2\% ao ano, alcançando um total de 922 milhões de turistas em 2008 (WTO, 2010). No ano 2012, apesar do contexto global de instabilidade 
econômica, o número de turistas no mundo superou pela primeira vez a barreira de um bilhão de pessoas. No Brasil, o crescimento experimentado nesse ano ultrapassou em $20 \%$ a média mundial (WTO, 2013).

O crescimento do turismo tem sido acompanhado por uma descentralização do fluxo turístico ao longo dos últimos sessenta anos. Assim, embora geograficamente e desde o ponto de vista da recepção o turismo seja um setor amplamente dominado pela hegemonia dos países do Norte, Europa e América do Norte entregaram parte da sua fatia de mercado para os países em desenvolvimento (WTO, 2010). Essa circunstância situa o turismo como uma atividade difusa no território, onde cada dia surgem novos destinos turísticos, e que ademais afeta transversalmente um número crescente de atividades e de estratos diversos da população (Córdoba, 2009).

Para várias instituições envolvidas com o turismo (MTUR e FGV, 2010; WTO, 2010) essa desconcentração do turismo mundial pode contribuir para a redução das desigualdades e para a promoção de um ambiente favorável ao desenvolvimento mais equilibrado. Nesse sentido, poderia se pensar que essa tendência caminha separada da tradicional interpretação dual do turismo, na qual este é considerado um fenômeno próprio de países ricos e um símbolo de prosperidade destinado a salvar as economias dos países pobres. Entretanto, analisando o impacto que o turismo gera nas diferentes economias pode observar-se que não mostra um comportamento similar. Assim, enquanto que nos países desenvolvidos o turismo tem possibilitado a abertura de novas zonas econômicas ou tem sido um elemento fundamental no cambio da estrutura econômica, nas economias emergentes e nos países em desenvolvimento o turismo, muitas vezes, se transforma apenas em um modelo de desenvolvimento alternativo, do momento, para se poder sair de situações adversas, implicando grandes transformações e impactos negativos (Dachary e Burne, 2006).

Hoje em dia não há dúvidas sobre a importância do turismo como atividade econômica, mas também como componente da estrutura territorial de numerosos lugares e regiões, pois é responsável por mudanças sociais e culturais nos destinos (Vera et al., 1997; Dias, 2003). O turismo é muito mais do que a soma de operações e elementos de caráter econômico. É o resultado da interação, na dupla perspectiva de causa ou de efeito, de inúmeros componentes ambientais, socioculturais e econômicos (Jafari, 1989; Buhalis, 2000). Por isso, sua compreensão não pode ser reducionista, baseada em uma ou outra definição ou na análise de suas partes isoladamente. O entendimento do turismo exige partir de uma visão integradora e interdisciplinar, que atenda aos mecanismos singulares de relações que acontecem entre os seus elementos (Beni, 2003).

Em função da complexidade da sua estrutura e das inter-relações entre os distintos componentes e fatores da atividade, a abordagem sistêmica vem sendo adotada para definir e entender o turismo, auxiliando a compreensão do contexto e retratando os relacionamentos entre as partes constituintes. Sua aplicação permite, dado um determinado objetivo, encontrar caminhos ou meios para alcançá-lo com a máxima eficiência e o mínimo custo, em uma rede de interações altamente complexa (Hall, 2001). Considerar o turismo desde os sistemas complexos é uma perspectiva que quebra com a visão dos esquemas lineares. Não significa isolar algum elemento afim de entendê-lo, senão assumir que o turismo é uma representação de um conjunto de situações, fenômenos e processos que não podem ser estudados prescindindo de suas interações com o resto. Implica, portanto, ir além da simples consideração de variáveis como oferta e demanda, na justificativa de um setor que tem como premissa a concorrência e homogeneização de produtos e serviços (Serrano-Barquín et al., 2011). Sob o enfoque sistêmico, o turismo pode ser analisado como um sistema aberto que se relaciona com o meio ambiente no qual se desenvolve a atividade, formalizando uma série de trocas. Isto é, o sistema exibe contínuos e permanentes processos de intercâmbios, tais como energéticos, materiais e de informações, e sem alguns deles, o sistema não sobrevive.

Atualmente, na literatura podem ser encontrados diversos modelos aplicados ao turismo que buscam compreender, representar e sistematizar tanto os elementos que caracterizam o fenômeno turístico quanto a suas inter-relações e sua relação com o ambiente externo. Os principais modelos existentes podem ser divididos em dois grupos: modelos espaciais e modelos estruturais. Como seu próprio nome indica, os modelos espaciais estão constituídos por elementos de caráter espacial, como por exemplo origem e destino, e concentram sua atenção na relação existente entre essas duas unidades geográficas (Leiper, 1979; Fuster, 1985; Palhares, 2002; Pearce, 2003). Já os modelos estruturais, incluem elementos relativos à oferta turística, e em alguns casos, também elementos vinculados à demanda, focalizando na inter-relação oferta-demanda (Inskeep, 1991; Moscardo et al., 1996; Hall, 2001; Beni, 2003). Com independência do modelo considerado, ver o turismo como um sistema aberto e integrado facilita os estudos multidisciplinares de aspectos particulares do fenômeno. Além disso, essa visão permite perceber a complexidade e variedade de todos os aspectos envolvidos no seu desenvolvimento assim como sua 
natureza dinâmica. Por sua vez, ambos os grupos de modelos abordam o turismo como uma atividade integrada a dimensões importantes para se discutir os impactos do turismo e a sustentabilidade: ambientes naturais, socioculturais e econômicos. Por fim, a abordagem sistêmica no turismo possibilita ressaltar a interdependência que existe entre vários elementos inter-relacionados e que deverão cooperar para cumprir objetivos comuns.

Atualmente o turismo apresenta-se como um complexo sistema de atividades encadeadas e, que está em processo constante de transformação, bem seja de demandantes, bem seja de fornecedores de serviços. É um fenômeno de interação entre o turista e o núcleo receptor e de todas as atividades decorrentes dessa interação. Nesse sentido, o turismo pode ser considerado um "bem construído", uma vez que sua oferta tem origem em um sistema que se constrói a partir de determinadas condições físicas, sociais, políticas e econômicas, se adaptando a diversas expectativas. Essa circunstância exige que a abordagem do turismo não se limite estritamente ao econômico, sendo necessário analisá-lo, sob a ótica da sustentabilidade, como um fenômeno complexo, detentor de outras dimensões - sociais, ambientais e culturais - permeadas de relações e no qual se produzem numerosos impactos inerentes à sua própria implementação, que deverão ser tratados de modo sistêmico.

\section{Turismo e sustentabilidade: uma relação paradoxal?}

O turismo faz uso de uma grande variedade de recursos naturais e patrimoniais que, em muitos casos, podem ser o atrativo principal de um destino. É amplamente reconhecida a capacidade que o turismo tem de alterar os sítios físicos e culturais que se tornam territórios da função turística (Mathieson e Wall, 1982; Leiper, 1995; Middleton e Hawkins, 1998; Lage e Milone, 2000; Swarbrooke, 2000). A experiência de muitos destinos turísticos demonstra que, se bem o turismo oferece novas possibilidades para o desenvolvimento das regiões, não se trata de uma atividade inofensiva, uma vez que, sobretudo a partir de certos níveis de visitantes e sem um planejamento adequado, pode induzir efeitos negativos. Assim, além da promoção de externalidades positivas, o turismo também pode gerar consequências sociais, econômicas e ambientais indesejáveis (Buhalis, 2000; Swarbrooke, 2000; Krippendorf, 2003).

A necessidade de reorientar as consequências negativas do modelo de desenvolvimento do turismo convencional, de massa, motivou que na década de 1990 como consequência dos debates posteriores à publicação do Relatório Brundtland, o turismo incorporasse o paradigma da sustentabilidade. Assim, o turismo sustentável surge como um remédio para atender as necessidades das diferentes partes envolvidas, minimizando os impactos negativos do turismo, enquanto busca otimizar os benefícios para o destino.

$\mathrm{Na}$ base da aparição do turismo sustentável como proposta alternativa de turismo mais respeitosa com o meio ambiente e mais responsável desde o ponto de vista social e econômico, escondem-se elementos de diferente natureza. Para Heras (2004, p.34) existem principalmente quatro razões que motivaram a origem do turismo sustentável, a saber: expansão da conscientização ambiental e proliferação do "sustentável" para todas as áreas e atividades humanas; percepção por parte dos turistas dos impactos que o turismo causa ao meio ambiente; maior exigência de qualidade nos destinos para lidar com a forte competitividade do mercado turístico; e aumento da pressão de grupos ambientalistas que passaram a reconhecer e se preocupar com os potenciais impactos do turismo.

A definição mais disseminada do turismo sustentável entende que é o turismo que atende as necessidades das gerações presentes sem comprometer a capacidade das gerações futuras de satisfazerem suas próprias necessidades, ao mesmo tempo em que evita ameaças econômicas, sociais e ambientais (WTO, 2004). Segundo essa definição o turismo sustentável tem como peça chave o equilíbrio de oportunidades e o uso racional dos recursos naturais, tentando manter a longo prazo a viabilidade da atividade e buscando uma relação mais produtiva e harmoniosa entre o visitante, a comunidade local e o lugar visitado.

O turismo sustentável reúne as três dimensões básicas da sustentabilidade. Isto é, reconhece a necessidade de valorizar as dimensões ambientais e socioculturais enquanto instrumento propiciador da produção de mudanças com efeitos de longo prazo. Por sua vez, considera o desejo de maximizar e distribuir os benefícios econômicos entre a comunidade receptiva, assim como a necessidade de satisfação de visitantes e comunidade anfitriã. O desenvolvimento turístico sustentável não implica apenas a conservação dos recursos naturais e culturais do destino e a minimização de possíveis impactos negativos, senão que se trata ao mesmo tempo de um mecanismo para que o destino se converta num referencial qualitativo para os visitantes. Nesse sentido, a definição de um desenvolvimento sustentável para o 
turismo implica necessariamente a inclusão de princípios éticos de reciprocidade, responsabilidade, adequação e correspondência entre expectativas e realizações (Swarbrooke, 2000; Ruschmann, 2002).

Contudo, embora o argumento para o turismo sustentável seja aparentemente claro e bastante razoável, o binômio turismo-sustentabilidade parece não se consolidar, padecendo de grandes limitações (Mowforth e Munt, 2003). Tal como acontece com o desenvolvimento sustentável, o turismo sustentável não é definido em termos precisos. Uma vez que é um conceito socialmente construído e que reflete os interesses e crenças de diferentes atores para atingir seus objetivos socioeconômicos e políticos, possui vários pontos de vista. Não há uma única definição, nem consenso sobre seus aspectos e critérios associados, o que deixa uma ampla margem para todo tipo de interpretações. Essa circunstância estaria transformando o turismo sustentável em um conceito maleável, incorporando muitas vezes na discussão premissas e argumentos falsos e, portanto, convertendo o debate sobre esse assunto em estéril e errado (Liu, 2003). Além disso, muitos dos problemas relacionados à ambiguidade do uso do conceito de desenvolvimento sustentável se devem a que frequentemente o termo é usado de maneira intercambiável, como sinônimo para formas específicas de turismo, tais como turismo alternativo, turismo verde, ecoturismo ou turismo brando, dentre outras (Clarke, 1997; Butler, 1999).

O conceito e as práticas para o desenvolvimento do turismo sustentável são geralmente interpretadas dentro de duas escolas básicas de pensamento. De um lado estão aqueles que consideram o turismo como um elemento fundamental nas políticas de desenvolvimento sustentável e fazem esforços na promoção do turismo sustentável. De outro, situam-se aqueles que enxergam o turismo como uma atividade profundamente dependente da lógica de mercado e, portanto, defendem que o turismo é incompatível com os princípios do desenvolvimento sustentável. Para estes últimos, o desenvolvimento sustentável no turismo ignora as características de produção e consumo do turismo e, por conseguinte, trata-se de um mito, uma jogada de marketing e reivindicação antiética (Sharpley, 2000; Mowforth e Munt, 2003; Lansing e Vries, 2006). Isto é, o turismo sustentável seria apenas uma estratégia de propaganda e de venda relacionada a modas de mercado para modelos inspirados no adjetivo verde ou na ecologia, mais que um compromisso real de mudança.

O turismo sustentável, semelhante ao próprio conceito de desenvolvimento sustentável, deve ser considerado desde uma perspectiva integral, conformada pelas dimensões ambiental, sociocultural e econômica. Mesmo assim, uma das críticas mais recorrentes dá conta de que as preocupações refletidas na literatura sobre a relação entre turismo e sustentabilidade tendem ainda a focar no meio ambiente físico e no produto (Sharpley, 2000). Essa atenção especial concedida às questões ambientais do destino estaria motivada pela facilidade na identificação dos impactos ambientais do turismo, mas impediria prestar atenção em outros aspectos essenciais como a viabilidade social e econômica da atividade. Críticas foram direcionadas também a percepção do turismo sustentável como um conceito definido sob a noção de equilíbrio no qual todos os elementos envolvidos funcionam de maneira coordenada e têm o mesmo valor (Landorf, 2001). Isso porque a grande quantidade e diversidade de interesses existentes no setor e a imprecisão dos termos e escala do seu alcance tornam pouco realista essa ideia.

$\mathrm{Na}$ discussão sobre a sustentabilidade no turismo emergem vários questionamentos, dentre eles: o que deve ser sustentável? Sustentável para quem? Sustentável por quanto tempo e em que condições? No entanto, a pergunta chave a ser respondida é se existe um turismo realmente sustentável. Ante esse questionamento, a resposta mais óbvia seria que o "verdadeiro desenvolvimento do turismo sustentável é inatingível" (Sharpley, 2000, p. 14). Mesmo assim, o comum é emitir um parecer parametrizado, considerando um destino ou um empreendimento mais sustentável do que outro. Isto é, por mais que exista um amplo leque de indicadores e certificações para avaliar e incentivar a sustentabilidade no desenvolvimento turístico, a singularidade de cada caso e a rede complexa de inter-relações entre os diversos componentes no sistema turístico inviabiliza a existência de uma resposta universal.

O que parece claro é que turismo sustentável não pode ser visto como um estado ideal, senão como "um processo de mudança qualitativa que oriente e reoriente o desenvolvimento turístico para objetivos alcançáveis" (Vignati, 2008, p. 28). Logo, a noção de sustentabilidade no turismo implica um processo contínuo de aperfeiçoamento ao qual deveriam aspirar todas as iniciativas de turismo, inclusive o turismo de massa, em todos os tipos de destino. Em outras palavras, a sustentabilidade não é uma característica exclusiva daquelas manifestações turísticas supostamente "alternativas", senão uma situação que se deveria alcançar para todas as formas de turismo independentemente da escala e do seu estado evolutivo. Afinal, o desafio pode ser desenvolver outro modelo de turismo ambientalmente mais benigno e que melhor se ajuste a critérios sociais e econômicos de um destino, independentemente do adjetivo usado para defini-lo. 


\section{A proposta do turismo de base comunitária como vetor da sustentabilidade}

A rápida implantação da atividade turística, especialmente em regiões menos favorecidas sob a ótica socioeconômica, não tem ocorrido a favor das populações locais, que ficam normalmente distantes do desenvolvimento do turismo. A exclusão das comunidades dos benefícios turísticos e o interesse na minimização dos efeitos nocivos da atividade sobre as populações locais estimularam uma nova forma de desenvolvimento do turismo que coloca a população local no centro do planejamento e promove práticas mais justas e sustentáveis. Junto a esses fatores, o crescimento da consciência crítica por parte dos turistas, unido à preocupação pelo turismo sustentável, abriu espaço para atividades turísticas de cunho social e ambiental, incentivando a necessidade de aproximação da atividade turística dos anseios da comunidade (Hiwasaki, 2006; Bursztyn e Bartholo, 2012).

Nesse contexto, diante das políticas hegemônicas de produção do espaço turístico e dentro de uma nova ordem mundial de desenvolvimento em busca da sustentabilidade econômica, ambiental e sociocultural, o turismo de base comunitária surgiu como uma alternativa e processo de resistência ao modelo de turismo convencional. Pode-se dizer que do turismo global emergiu um turismo local, em um processo de desenvolvimento desde abaixo, voltado para os interesses das comunidades que tradicionalmente têm sido tratadas como objetos e não como sujeitos do desenvolvimento turístico (Ruiz et al., 2008; Irving, 2009).

O TBC incorpora o estabelecimento de novas formas de trabalho baseadas na colaboração em prol de objetivos comuns. Isto é, coloca em prática um planejamento fundamentado em um exercício consciente de corresponsabilidade, participação local e governança compartilhada, com o objetivo de, além de dar resposta à demanda dos visitantes, conciliar o desenvolvimento local e a conservação da natureza. Trata-se, portanto, de uma prática turística nascida da percepção das próprias comunidades de que é necessário vivenciar outra lógica de atividade turística.

Dessa forma, o turismo de base comunitária emerge inicialmente nos países em desenvolvimento como um novo modelo turístico mais justo e equitativo do que os projetos turísticos tradicionais, alicerçado nos princípios do desenvolvimento sustentável e associado à inclusão social (Manyara e Jones, 2007; Bartholo, Sansolo e Bursztyn, 2009). No Brasil, o TBC se apresenta como uma proposta crescente em todo o país, desenvolvendo-se com maior intensidade em áreas protegidas e espaços rurais que, em sua maioria, albergam comunidades com poucas perspectivas econômicas. Igualmente, a grande maioria de iniciativas de TBC se encontra em regiões próximas a destinos consolidados e depende de uma interação com esses destinos para se desenvolver, uma vez que poucas iniciativas de TBC são capazes de atrair os turistas por si mesmas (MTUR, 2010).

Apesar do crescimento significativo dessas atividades turísticas em diferentes comunidades, não existe uma única definição conceitual do TBC amplamente aceita. Por trás dessa falta de consenso pode-se esconder precisamente a heterogeneidade das experiências que se desenvolvem em comunidades de diversas configurações, fazendo com que o "turismo de base comunitária signifique coisas diferentes para pessoas diferentes" (Kiss, 2004: 232). Contudo, na tentativa de ilustrar a diversidade de interpretações sobre o TBC, ainda que com similaridades enquanto princípios e dimensões, o Quadro 1 abaixo reúne diversas definições apresentadas por diferentes instituições, experiências e autores.

Ao contrário do turismo convencional, pautado pela lógica do mercado e que visa principalmente o lucro mediante a produção e consumo dos destinos, o TBC assenta-se nos princípios da economia solidária. Mediante a gestão turística sob controle das comunidades receptoras, o turismo comunitário enfatiza a conservação ambiental e a valorização da identidade cultural, se caracterizando por práticas democráticas de trabalho e a distribuição equitativa das riquezas geradas pela atividade. Além disso, o modelo de TBC considera o turismo como uma atividade complementar, e não como a única alternativa econômica, realizada de forma integrada às tradicionais ocupações desenvolvidas pela comunidade e que, por sua vez, pode ser também um meio para alcançar objetivos sociais e ambientais.

Frequentemente o TBC é considerado uma importante ferramenta para a luta contra a pobreza, se associando quase exclusivamente à geração de emprego e renda. Entretanto, diversos autores (Irving, 2002; Coriolano e Lima, 2003) chamam a atenção para a necessidade de vincular o TBC a uma perspectiva mais ampla do desenvolvimento que atenda as expectativas de bem-estar social das comunidades e de qualidade ambiental do local onde estas se inserem. Nesse sentido o TBC poderia ser interpretado como um subsistema interconectado a outros subsistemas, como a educação, a saúde ou o meio ambiente, entre outros. Da mesma forma, tampouco parece acertado reduzir o modelo de TBC a formas alternativas de turismo, nem tratá-lo como um segmento de mercado, mas sim abordá-lo como uma metodologia de 
trabalho e proposta de desenvolvimento para o turismo, apoiada em bases endógenas e que pode ser aplicada a diversos segmentos turísticos (Fabrino, Costa e Nascimento, 2012; Mielke e Pegas, 2013).

\section{Quadro 1. Definições do turismo de base comunitária}

\begin{tabular}{|c|c|}
\hline Instituição/Associação/Autor & Definição \\
\hline World Trade Organization (WTO) & $\begin{array}{l}\text { "Uma interação visitante/anfitrião, cuja participação é significativa } \\
\text { para ambos e gera benefícios econômicos e de preservação para as } \\
\text { comunidades e o meio ambiente local". UNCTAD/WTO (2005: } 27)\end{array}$ \\
\hline $\begin{array}{l}\text { World Wildlife Fund } \\
\text { (WWF-Brasil) }\end{array}$ & $\begin{array}{l}\text { "Turismo realizado em áreas naturais, determinado e controlado pelas } \\
\text { comunidades locais, que gera benefícios predominantemente para estas } \\
\text { e para as áreas relevantes para a conservação da biodiversidade". } \\
\text { WWF (2003: 23) }\end{array}$ \\
\hline $\begin{array}{l}\text { Ministério do Turismo } \\
\text { (MTur-Brasil) }\end{array}$ & $\begin{array}{l}\text { "O turismo de base comunitária é compreendido como um modelo de } \\
\text { desenvolvimento turístico, orientado pelos princípios da economia } \\
\text { solidária, associativismo, valorização da cultura local, e, principalmente, } \\
\text { protagonizado pelas comunidades locais, visando à apropriação por parte } \\
\text { dessas dos benefícios advindos da atividade turística". (MTur, 2008: 1) }\end{array}$ \\
\hline $\begin{array}{l}\text { Rede Cearense de Turismo } \\
\text { Comunitário - TUCUM }\end{array}$ & $\begin{array}{l}\text { "Aquele no qual, as populações locais possuem o controle efetivo sobre } \\
\text { o seu desenvolvimento e gestão, está baseado na gestão comunitária ou } \\
\text { familiar das infraestruturas e serviços turísticos, no respeito ao meio } \\
\text { ambiente, na valorização da cultura local e na economia solidária". } \\
\text { (TUCUM, 2008, apud Sansolo e Bursztyn, 2009: 147) }\end{array}$ \\
\hline Prainha do Canto Verde & $\begin{array}{l}\text { "Turismo Comunitário é uma oportunidade para aperfeiçoar a organização } \\
\text { comunitária, o desenvolvimento local e a cogestão para preservar } \\
\text { o patrimônio natural, cultural e as formas de vida tradicionais das } \\
\text { comunidades e do seu território". (http://prainhadocantoverde.org) }\end{array}$ \\
\hline Coriolano & $\begin{array}{l}\text { "O turismo comunitário é aquele em que as comunidades de forma } \\
\text { associativa organizam arranjos produtivos locais, possuindo o controle } \\
\text { efetivo das terras e das atividades econômicas associadas à exploração } \\
\text { do turismo". (Coriolano, 2009: 282) }\end{array}$ \\
\hline Irving & $\begin{array}{l}\text { "Aquele tipo de turismo que, em tese, favorece a coesão e o laço social e } \\
\text { o sentido coletivo de vida em sociedade, e que por esta via, promove a } \\
\text { qualidade de vida, o sentido de inclusão, a valorização da cultura local } \\
\text { e o sentimento de pertencimento". (Irving, 2009: 111) }\end{array}$ \\
\hline
\end{tabular}

Fonte: Elaboração própria a partir de informações dos autores citados.

Ainda que todas as modalidades turísticas devessem ser sustentáveis, o turismo de base comunitária acolhe a sustentabilidade como razão de ser e compromisso central em seu planejamento. O TBC representa a promoção de atividades turísticas enraizadas em um modelo de desenvolvimento socialmente mais justo e ambientalmente responsável. Em resumo, o TBC mantém vínculos não só com a dimensão ambiental da sustentabilidade, como também com a dimensão sociocultural, através do estímulo de trocas culturais entre visitantes e moradores, podendo igualmente apontar caminhos frutíferos para a melhoria da qualidade de vida e do bem-estar da população receptora.

A característica fundamental e o que verdadeiramente torna singulares as experiências de turismo de base comunitária é o protagonismo das comunidades locais na gestão da atividade, por meio da organização e participação social, assim como o predomínio das relações sociais nos serviços turísticos implementados: "é a comunidade no turismo e não tanto o turismo na comunidade o determinante no TBC" (Ruiz et al., 2008: 400). Na medida em que potencializa o grau de participação dos atores locais nas decisões sobre seu futuro e sua interação na construção de objetivos comuns, o planejamento turístico de base comunitária procura estimular, por conseguinte, um maior envolvimento popular nas decisões políticas, sociais e econômicas de uma determinada comunidade. Ao final, a perspectiva da gestão participativa no processo de planejamento, implementação e avaliação de projetos turísticos, representa um fator critico para o desenvolvimento 
sustentável do turismo. Desta forma, a participação das populações locais pode ajudar a coexistência do desenvolvimento do turismo, da qualidade ambiental dos destinos e do bem-estar das comunidades.

\section{Participação social: garantia de sustentabilidade turística?}

No arcabouço teórico do turismo, a interface com a participação aparece como tema recorrente, surgindo como elemento fundamental para a criação de condições favoráveis para o desenvolvimento do turismo sustentável (Hall, 2001; Choi e Sirakaya, 2006; Tosun, 2006). Já no turismo de base comunitária, a participação é coerente com as perspectivas de desenvolvimento perseguidas por esse modelo, uma vez que ele se fundamenta na criação de produtos e serviços turísticos protagonizados pelas comunidades receptoras, visando à apropriação, por parte destas, dos benefícios advindos do desenvolvimento do setor.

Mesmo assim, a participação apresenta-se como um termo ideologicamente ambíguo, uma espécie de guarda-chuva no qual encaixam muitas práticas, uma vez que pode servir a vários propósitos. Se por um lado a participação pode ser implantada com objetivos de liberação e igualdade, dentro de um processo transformador que conduza os indivíduos ao exercício pleno de sua cidadania, por outro também pode ser fomentada para a manutenção de uma situação de controle, através de ações verticalizadas que busquem apenas valer-se da comunidade para validar atuações pré-estabelecidas por atores externos. Dito de outra forma, a participação pode servir desde a emancipação de atores sociais até a cooptação, dependendo da forma de aplicação e da concepção de desenvolvimento no qual acontece (Cooke e Kothari, 2001).

A participação faz parte das necessidades humanas universais e implica uma ação coletiva com certo grau de organização, dentro de um processo social transformador que integra múltiplas escalas e dimensões. Por meio da noção de participação é possível entender os princípios que regem a integração entre os indivíduos de uma determinada sociedade. Como processo coletivo transformador, a participação visa a incorporação de setores marginalizados à vida social, por direito próprio e não apenas como convidados, conquistando a presença ativa e decisória nos processos de interesse da sociedade. Portanto, a participação pode ser interpretada como um contraponto à marginalização, entendendo esse elemento como o resultado lógico e natural do desenvolvimento da modernidade, onde há desigualdade de acesso aos benefícios para que uns possam acumular, enquanto outros são explorados (Bordenave, 1994). Isto indica que a participação está estreitamente ligada ao TBC, uma vez que essa proposta nasce precisamente como resposta à marginalização das comunidades frente a um assunto como o turismo que, sendo de interesse global, tem geralmente excluído a perspectiva local. Assumindo o planejamento, implementação e monitoramento da atividade turística as comunidades passariam então a superar sua condição de sobrevivência num contexto tradicionalmente de exclusão, tornando-se protagonistas do seu próprio bem-estar.

A participação compreende todas as formas e meios pelos quais os membros de um grupo, como indivíduos ou coletividade, podem influenciar os destinos do próprio grupo. Assim, na vida social ela pode assumir várias formas que estão relacionadas à complexidade e o grau de controle sobre as decisões. As diferentes posições participativas adotadas pelos membros refletem-se no padrão da qualidade participativa do grupo. Tais posturas poderão estar relacionadas a diversos graus de lealdade, comprometimento perante o grupo, vínculos afetivos e interesses pessoais, dentre outros. Ainda, benefícios percebidos e custes potenciais, assim como o apego da comunidade e sua satisfação no projeto, são fatores essenciais que condicionam o nível de apoio dos residentes locais no desenvolvimento de práticas turísticas sustentáveis (Lee, 2013; Nunkoo e Ramkissoon, 2011). Contudo, interessa salientar que, acima de tudo, a qualidade participativa não é dada, senão conquistada, pois "a participação é um processo de conquista e construção organizada da emancipação social” (Demo, 2001: 36).

$\mathrm{Na}$ tentativa de ilustrar diferentes modelos de participação comunitária no processo de desenvolvimento turístico, Tosun (2006) compara sua própria proposta de tipologia de participação (Tosun, 2000) com as de outros dois autores (Arnstein, 1969; Pretty, 1995), encontrando coincidências no espectro da participação e suas implicações. Por sua vez, Biggs (1989) classifica diferentes modos de participação comunitária quanto as suas características em quatro níveis, a saber: contratual, consultiva, colaborativa e colegial. O Quadro 2 resume as principais características das tipologias de participação comunitária apresentadas por esses autores. Nos modelos comparados os graus de controle dos membros da comunidade partem do menor nível, onde a comunidade apenas é um ator passivo dentro de um contexto de participação simulado, com decisões já previamente tomadas; passam pela consulta facultativa, com a comunidade ganhando poder, mas ainda dentro de um processo algo funcional e materialmente incentivado; e terminam 
no grau mais elevado de participação comunitária, o controle da comunidade, autentica participação onde o grupo determina seus objetivos, escolhe seus meios e estabelece os controles pertinentes.

\section{Quadro 2. Tipologias de participação comunitária}

\begin{tabular}{|c|c|c|c|c|}
\hline $\begin{array}{l}\text { Tipologia da } \\
\text { participação } \\
\text { comunitária de } \\
\text { Pretty (1995) }\end{array}$ & \multicolumn{2}{|c|}{$\begin{array}{c}\text { Tipologia da participação comunitária } \\
\text { de Arnstein (1969) }\end{array}$} & $\begin{array}{l}\text { Tipologia da } \\
\text { participação } \\
\text { comunitária de } \\
\text { Tosun (2000) }\end{array}$ & $\begin{array}{c}\text { Tipologia de } \\
\text { participação } \\
\text { comunitária de } \\
\text { Biggs (1989) }\end{array}$ \\
\hline $\begin{array}{l}\text { 1. Manipulada } \\
\text { 2. Passiva }\end{array}$ & 1. Manipulação & Não-participação & $\begin{array}{l}\text { Coercitiva: de } \\
\text { cima para baixo; } \\
\text { passiva; indireta, } \\
\text { oficial; apenas na } \\
\text { implementação, mas } \\
\text { não necessariamente } \\
\text { na distribuição de } \\
\text { benefícios; limitada } \\
\text { nas alternativas } \\
\text { ou sem eleição; } \\
\text { paternalismo, } \\
\text { não participação, } \\
\text { elevados graus } \\
\text { de formalismo e } \\
\text { manipulação. }\end{array}$ & $\begin{array}{l}\text { Contratual: um } \\
\text { grupo ou ator social } \\
\text { acumula o poder e } \\
\text { lidera o projeto. }\end{array}$ \\
\hline \multirow{3}{*}{$\begin{array}{l}\text { 3. Por consulta } \\
\text { 4. Por incentivos } \\
\text { materiais } \\
\text { 5. Funcional }\end{array}$} & 3. Informação & \multirow[b]{3}{*}{$\begin{array}{l}\text { Graus de formalismo } \\
\text { cidadã }\end{array}$} & \multirow{3}{*}{$\begin{array}{l}\text { Induzida: de cima } \\
\text { para baixo; } \\
\text { passiva, oficial; } \\
\text { indireta; formal, } \\
\text { manipulada;pseudo- } \\
\text {-participação; } \\
\text { participação na } \\
\text { implementação } \\
\text { e distribuição de } \\
\text { benefícios; escolha } \\
\text { entre alternativas } \\
\text { propostas e } \\
\text { retroalimentação. }\end{array}$} & \multirow{3}{*}{$\begin{array}{l}\text { Consultiva: um } \\
\text { grupo ou ator } \\
\text { toma as decisões } \\
\text { essenciais, mas } \\
\text { consultando } \\
\text { as opiniões e } \\
\text { necessidades do } \\
\text { resto de membros. }\end{array}$} \\
\hline & 4. Consulta & & & \\
\hline & 5. Pacificação & & & \\
\hline \multirow{4}{*}{$\begin{array}{l}\text { 6. Interativa } \\
\text { 7. Automobilização }\end{array}$} & 6. Parceria & \multirow{4}{*}{$\begin{array}{l}\text { Graus de poder } \\
\text { cidadã }\end{array}$} & \multirow{4}{*}{$\begin{array}{l}\text { Espontânea: de } \\
\text { baixo para cima; } \\
\text { ativa e direta; } \\
\text { decisória; autentica; } \\
\text { autoplanejada. }\end{array}$} & \multirow{2}{*}{$\begin{array}{l}\text { Colaborativa: } \\
\text { equidade na } \\
\text { distribuição de } \\
\text { poder na tomada de } \\
\text { decisões. }\end{array}$} \\
\hline & \multirow[t]{2}{*}{$\begin{array}{l}\text { 7. Delegação de } \\
\text { poder }\end{array}$} & & & \\
\hline & & & & Colegial: \\
\hline & $\begin{array}{l}\text { 8. Controle do } \\
\text { cidadão }\end{array}$ & & & $\begin{array}{l}\text { distribuídas por } \\
\text { igual; decisões } \\
\text { tomadas por } \\
\text { consenso; ideal. }\end{array}$ \\
\hline
\end{tabular}

Fonte: Adaptado de Tosun (2006) e Biggs (1989).

Diante disso, nem todas as formas de participação de uma comunidade no desenvolvimento turístico poderão contribuir para a obtenção dos benefícios esperados pelo TBC, uma vez que a participação pode assumir várias aparências, que vão desde a participação manipulada até o verdadeiro poder cidadão. Assume-se, ao menos no discurso teórico, que o TBC é um modelo turístico no qual as populações locais, através de uma estrutura organizacional, têm uma possibilidade maior de possuir um controle efetivo sobre o desenvolvimento e gestão do turismo, articulando-se e buscando o benefício comum. Esse 
controle por parte das comunidades sobre os processos de planejamento e gestão da atividade ofereceria diversas vantagens. Como conhecedoras da sua realidade imediata, as comunidades poderiam ajudar a identificar problemas e necessidades, avaliar alternativas, desenvolver estratégias para a proteção e/ou valorização do patrimônio natural e cultural, e buscar soluções para os problemas identificados (Irving et al., 2005). Mediante a participação comunitária, tem-se, portanto, a possibilidade maior de desenvolver e proteger os ativos da comunidade, assim como de assegurar uma distribuição mais equitativa dos benefícios turísticos, aumentando a viabilidade e longevidade dos projetos e melhorando a qualidade de vida das populações locais.

A participação no turismo está determinada pelo conjunto de relacionamentos que existem entre as várias partes interessadas e pelo grau em que esses relacionamentos são exclusivos ou inclusivos (Hall, 2001). No turismo comunitário ela é o preparo e habilidade das comunidades para administrar serviços e recursos. Por conseguinte, será o resultado, entre outros fatores, dos arranjos dos membros da comunidade, das estruturas de poder, dos interesses e valores que afetam o processo de tomada de decisão, e da capacidade dos indivíduos e grupos de se envolverem. Quanto a tal assunto, vale ressaltar que o acesso à educação é considerado elemento fundamental para o processo participativo (Bordenave, 1994). No contexto do TBC a componente educacional na comunidade se apresenta, por seu caráter integrador e multidisciplinar, como condição básica para garantir a participação das populações locais no desenvolvimento de projetos turísticos comunitários e, conseqüentemente, para ter maiores oportunidades de sucesso (Rivera-Mateos e Rodríguez-García, 2012).

Sem dúvida, a participação social no turismo de base comunitária deve ser vista como um instrumento importante para promover a articulação entre os atores sociais, fortalecendo a coesão da comunidade, e para melhorar a qualidade das decisões, tornando mais fácil o alcance de objetivos de interesse comum. Comumente o discurso do TBC se apropria da noção de participação como uma qualidade intrínseca ao modelo e indistintamente aplicável a qualquer experiência. No entanto, considera-se oportuno acrescentar alguns questionamentos que envolvem a concepção e o significado de participação no âmbito do TBC de modo a incentivar a reflexão sobre a relação entre esse conceito e a sustentabilidade turística. A maior parte destas "suspeitas" sobre participação poderiam ser agrupadas sob o apelativo de "mito da comunidade", uma vez que no TBC a comunidade se identifica como espaço ideal para a prática participativa (Cleaver, 1999).

O primeiro questionamento está relacionado ao poder e aos processos de decisão que acontecem no interior de uma comunidade e que quebram com a ideia de harmonia e coesão. A concepção homogênea de comunidade está baseada em uma leitura simplista e romântica, desconsiderando a estratificação e as relações de poder estabelecidas (Blackstock, 2005). Conforme essa autora, o controle local da atividade turística não leva automaticamente à tomada de decisão participativa, já que essa participação depende das desigualdades estruturais inerentes à comunidade. Todavia, a autora destaca que a ação da comunidade sob o discurso de "interesse comunitário" pode refletir apenas os interesses daqueles em posição de poder, mascarando motivações econômicas desses atores, e não o bem coletivo. Isto é, as comunidades raramente falam em uma só voz e as relações de poder são capazes de alterar os resultados dos esforços ou impedir a ação participativa. Nesta mesma linha de argumentação, Cornwall e Jewkes (1995) defendem que dentro de uma comunidade as pessoas estão associadas por meio de várias redes sobrepostas com diversas ligações em torno de interesses diferentes que condicionarão a ação participativa.

O segundo aspecto a ressaltar são os limites sobre a participação social impostos desde fora da comunidade, pois sua capacidade de atuação não depende apenas de si mesma. Deste modo, além da compreensão da divisão estrutural interna das comunidades, é necessário considerar a existência de barreiras externas à participação e controle local (Blackstock, 2005; Tosum, 2006). A posição das comunidades turísticas por vezes é estruturalmente fraca diante da rede do capital global, que dita as regras da indústria do turismo, impedindo a autonomia na tomada de decisões em nível local e, no fim, tem a capacidade de determinar o destino das comunidades. Desta forma, no contexto da atual globalização, uma comunidade, mesmo tendo iniciativa participativa, pode ver-se impedida de tomar as rédeas de seu próprio desenvolvimento turístico.

Por fim, o terceiro questionamento sobre a participação comunitária tem a ver com a predisposição em apresentar o TBC como uma proposta de desenvolvimento turístico que envolve a comunidade como um todo, assumindo que todos os membros estão comprometidos e têm uma atuação ativa em defesa dos interesses coletivos. Entretanto, em muitas experiências o turismo de base comunitária não envolve todos os membros da comunidade e sim um grupo, por vezes pequeno, de moradores. Essa circunstância pode provocar repensar o verdadeiro sentido coletivo da expressão "base comunitária", enquanto o termo reforça essa impressão de envolvimento da comunidade como um todo, embora muitas 
vezes não seja condizente com as iniciativas em curso. Além disso, apesar de ser possível que todos ou a grande maioria dos membros de uma comunidade estejam dispostos a participar, surge a dúvida se isso, por si, já assegura o controle local e a sustentabilidade da atividade. A esse respeito, diversos autores (Blackstock, 2005; Mowforth e Munt, 2003) alertam para a hipótese geral de que quanto maior a participação, maior será a sustentabilidade turística, desde que o simples envolvimento de uma elevada porcentagem de membros de uma comunidade em projetos turísticos não conduz invariavelmente a uma gestão turística baseada em decisões consensuais e democráticas, sem riscos de conflito.

Cabe então admitir que a participação não é uma forma de ação homogênea e que não se pode falar de participação "ideal". Ela pode adotar diferentes formas que dependem da estrutura relacional da comunidade, das relações de poder internas e externas, e das aspirações da comunidade no processo de desenvolvimento. Igualmente, a participação deve se adaptar às características locais de cada comunidade, de modo a introduzir diferentes atores nos processos estratégicos de maneiras distintas. Ainda, a participação envolve alguns custos, e se não for organizada e executada cuidadosamente, pode inclusive ser contraproducente (Meadowcrof, 2003). Parece necessário, portanto, reconhecer a necessidade de se observar a realidade, interpretando cuidadosamente cada caso em função das circunstâncias específicas de cada contexto para fugir, justamente, da participação na sustentabilidade turística apenas como discurso.

\section{Considerações finais}

A atividade turística vem ganhando importância em todo o mundo principalmente em função do seu papel no desenvolvimento econômico. Entretanto, trata-se de um fenômeno complexo que vai além da simples prática de mercado. Desta maneira, embora se reconheça a importância econômica da atividade, sua aproximação desde a perspectiva da sustentabilidade exige superar apenas as implicações comerciais ou empresariais para incorporar as dimensões ambiental e sociocultural, assim como suas inter-relações.

O enfoque sistêmico auxilia no entendimento do turismo como fenômeno complexo a partir do relacionamento entre as partes constituintes, possibilitando destacar a interdependência entre os diferentes elementos que deverão colaborar para cumprir objetivos comuns. Além disso, essa abordagem está diretamente vinculada à ideia de sustentabilidade no turismo, permitindo salientar os numerosos impactos decorrentes da sua própria implementação e tratá-los de forma integral.

O turismo sustentável surge como um remédio para atender as necessidades das diferentes partes envolvidas na atividade, minimizando os impactos negativos, enquanto busca otimizar os benefícios para o destino. Porém, como desdobramento do desenvolvimento sustentável, acredita-se que a utilização banalizada e indiscriminada da sustentabilidade no turismo, assim como sua adoção sem refletir sobre o que verdadeiramente significa e a quem beneficia, enfraquece a discussão do turismo como fator de desenvolvimento. Igualmente, vincular a sustentabilidade apenas a modalidades alternativas de turismo simplifica a realidade, reduzindo as possibilidades de compreendê-lo e ocultando os problemas que envolve sua prática, correndo também o risco de perpetuar um discurso vazio. Deste modo, considera-se que a sustentabilidade não pode ser vista como um estado ideal ou atributo intrínseco a determinada modalidade turística, mas sim um padrão de desenvolvimento que deveria ser alcançado para todas as iniciativas de turismo.

Mais do que se perguntar se um destino ou proposta turística é sustentável, entende-se que talvez seja melhor indagar sobre as ações que podem levar a resultados compatíveis com o que se espera da sustentabilidade na construção de um destino ou experiência turística. A este respeito, a inclusão e a participação das comunidades locais no desenvolvimento do turismo ganha cada vez mais força como parte integral da sustentabilidade turística. Defende-se que mediante a participação comunitária no turismo aumenta-se a probabilidade de respeito aos estilos de vida e valores locais, além da criação de melhores oportunidades para que as comunidades obtenham mais benefícios das atividades turísticas que ocorrem em suas localidades. Igualmente, considera-se que a abordagem participativa pode aumentar a capacidade de carga e o ciclo de vida de um destino turístico reduzindo os impactos negativos da atividade e melhorando simultaneamente seus efeitos positivos.

O turismo de base comunitária acolhe a participação social como compromisso central do planejamento e gestão da atividade. Ainda que o universo do TBC seja heterogêneo, o elemento fundamental que caracteriza todas as propostas que se desenvolvem sob essa denominação é a preponderância dos padrões relacionais interpessoais na gestão dos recursos e serviços turísticos. Não obstante, acredita-se que frequentemente o discurso do TBC se apropria da noção de participação como uma qualidade 
intrínseca ao modelo e indistintamente aplicável a qualquer experiência, sem levar em consideração as características da gestão participativa desde uma verdadeira perspectiva relacional, nem valorar possíveis entraves ao processo participativo próprios de cada caso.

Por fim, considera-se que o sucesso da gestão participativa na prática do TBC depende do grau de apropriação do projeto por parte da comunidade, assim como das desigualdades de poder existentes e que podem dificultar a participação de várias partes interessadas. A participação social no TBC não implica que todos ou a maioria dos membros de uma comunidade trabalhem ou participem ativamente dentro da estrutura organizativa e operativa do TBC, tampouco que o façam com o mesmo grau de envolvimento social na toma de decisões. As comunidades estão constituídas por grupos com diversos interesses e graus de poder, de modo que uma ampla participação no desenvolvimento do TBC não tem porque significar um controle baseado em decisões consensuais e tampouco implicar menores riscos de conflito ou maior eficiência da prática turística. A este respeito, a avaliação da gestão participativa no TBC requer considerar, além da porcentagem de atores envolvidos, outras variáveis, tais como o nível de participação dos membros e a estrutura social da comunidade, em relação as assimetrias e relações de poder.

Para concluir, acredita-se que, apesar de enraizado em um modelo de desenvolvimento socialmente mais justo e ambientalmente responsável, o TBC não deveria ser tratado como uma panaceia para o desenvolvimento das comunidades nem para a busca de tão sonhada sustentabilidade, e sim como uma oportunidade de desenvolvimento para uma comunidade organizada.

\section{Bibliografia}

Arnstein, S. R.

1969. "A Ladder of Citizen Participation”. JAIP, 35(4): 216-224.

Bartholo, R. S., Sansolo, D. G. e Buszrtyn, I.

2009 Turismo de base comunitária: diversidade de olhares e experiências brasileiras. Rio de Janeiro:

Letra e Imagem.

Beni, M. C.

2003 Análise Estrutural do Turismo. São Paulo: SENAC.

Biggs, S. D.

1989 Resource-poor farmer participation in research: A synthesis of experiences from nine national

agricultural research systems. OFCOR Comparative Study Paper 3. Hague: INSAR. Blackstock, K.

2005 "A critical look at community based tourism". Community Development Journal, 40(1): 39-49.

Bordenave, J. E. D.

1994 O que é participação? São Paulo: Brasiliense.

Buhalis, D.

2000 "Marketing the Competitive Destination of the future". Tourism Management, 21: 97-116.

Bursztyn, I. e Bartholo, R.

2012 "O processo de comercialização do turismo de base comunitária no Brasil: desafios, potencialidades

e perspectivas”. Sustentabilidade em Debate, 3(1): 97-116.

Butler, R.

1999 "Sustainable tourism: A state-of-the-art review". Tourism Geographies, 1(1): 7-25.

Choi, H. and Sirakaya, E.

2006 "Sustainability indicators for managing community tourism". Tourism management, 27: 1274-1289.

Clarke, J. A.

1997 "Framework of Approaches to Sustainable Tourism". Journal of Sustainable Tourism, 5(3): 224-233.

Cleaver, F.

1999 "Paradoxes of participation: questioning participatory approaches to development". Journal of

International Development, 11: 597-612.

Cooke, B. and Kothari, U.

2001 Participation, The New Tirany. London: Zed Books.

Córdoba, J.

2009 “Turismo, desarrollo y disneyzación: una cuestión de recursos o de ingenio?". Investigaciones

Geográficas, 70: 33-54.

Coriolano, L. N.

2009 Arranjos produtivos Locais do Turismo Comunitário: atores e cenários em mudanças. Fortaleza:

UECE. 
Coriolano, L. N. e LIMA, L. C.

2003 Turismo comunitário e responsabilidade socioambiental. Fortaleza: EDUECE.

Cornwall, A. and Jewkes, R.

1995 “What is participatory research?". Social Science \& Medicine, 41(12): 1667-1676.

Dachary, A. C. y Burne, S. M.

2006 "El estudio del turismo: un paradigma en formación?". Estudios y Perspectivas en Turismo, 15: 179-192.

Demo, P.

2001 Participação é conquista: noções de política social participativa. São Paulo: Cortez.

Dias, R.

2003 Turismo sustentável e meio ambiente. São Paulo: Altas.

Fabrino, N. H., Costa, H. A. e Nascimento, E. P.

2012 "Turismo de Base Comunitária (TBC): elementos chaves para aferir seu desempenho na perspectiva da sustentabilidade”. Revista Brasileira de Ecoturismo, 5(3): 546-559.

Fuster, F.

1985 Introducción a la teoría y técnica del turismo. Madrid: Alianza.

Garrod, B. and Fyall, A.

1998 "Beyond the Rhetoric of Sustainable Tourism?". Tourism Management, 19(3): 199-212.

Hall, M. C.

2001 Planejamento turístico: políticas, processos e relacionamentos. São Paulo: Contexto.

Heras, M. P.

2004 Manual de turismo sostenible: cómo conseguir un turismo social, económico y ambientalmente responsable. Madrid: Mundi-Prensa.

Hiwasaki, L.

2006 "Community-based tourism: A pathway to sustainability for Japan`s protected areas". Society and Natural Resources, 19: 133-143.

Inskeep, E.

1991 Tourism Planning: An integrated and sustainable development approach. New York: Van Nostrand Reinhold.

Irving, M. A.

2002 "Participação: questão central na sustentabilidade de projetos de desenvolvimento". In Irving,

M. A. e Azevedo, J. (Orgs.), Turismo, o desafio da sustentabilidade (pp.35-45). São Paulo: Futura.

Irving, M. A.

2009 "Reinventando a reflexão sobre turismo de base comunitária: inovar é possível?". In Bartholo,

R., Sansolo, D.G. e Bursztyn, I. (Orgs.), Turismo de base comunitária: Diversidade de olhares e experiências brasileiras (pp. 108-119). Rio de Janeiro: Letra e Imagem.

Irving, M. A., Bursztyn, I., Sancho, A. P. e Melo, G. M.

2005 "Revisitando significados em sustentabilidade no planejamento turístico". Caderno Virtual de Turismo, 5(4): 1-7.

Jafari, J.

1989 "Sctructure of Tourism". In Witt, S. and Moitinho, L. (Eds.), Tourism Marketing and Management Handbook (pp. 437-442). UK: Prentice Hall International.

Jones, S.

2005 "Community-based ecotourism the significance of social capital". Annals of Tourism Research, 32: 303-324.

Kiss, A.

2004 Is community-based ecotourism a good use for biodiversity conservation funds? Trends in Ecology and Evolution, 19(4): 232-237.

Krippendorf, J.

2003 Sociologia do Turismo: por uma nova compreensão do lazer e das viagens. São Paulo: Aleph.

Lage, B. H. G. e Milone, P. C.

2000 Turismo: teoria e prática. Editora Atlas: São Paulo.

Landorf, C.

2001 Economia do turismo. São Paulo: Atlas.

Lansing, P. and Vries, P.

2006 “Sustainable Tourism: Ethical Alternative or Marketing Ploy?". Journal of Business Ethics, 72: 77-85.

Lee, T. H. 
2013 "Influence analysis of community resident support for sustainable tourism development". Tourism

Management, 34: 37:46.

Leiper, N.

1979 "The Framework of Tourism". Annals of Tourism Research, 6(4): 390-407.

Liu, Z.

2003 "Sustainable tourism development: a critique". Journal of Sustainable Tourism, 11(6): 459-475.

Manyara, G. and Jones, E.

2007 "Community-based tourism enterprises development in Kenya: An exploration of their potential

as avenues of poverty reduction”. Journal of Sustainable Tourism, 15(6): 628-644.

Mathieson, A. and Wall, G.

1982 Tourism: Economic, Physical and Social Impacts. Harlow: Longman.

Meadowcroft, J.

2003 "Participación y estrategias para el desarrollo sostenible". Revista Instituciones y Desarrollo,

14: 123-138.

Middleton, V. and Hawkins, R.

2009 Sustainable tourism: a marketing perspective. Oxford: Butterworth-Heinemann.

Mielke, E. J. C.

2009 Desenvolvimento Turístico de Base Comunitária. Campinas: Alínea.

Mielke, E. J. C. e Pegas, F. V.

2013 “Turismo de Base Comunitária no Brasil. Insustentabilidade é uma Questão de Gestão". Turismo em Análise, 24(1): 170-189.

Moscardo, G., Morrison, A. M., Pearce, P. L., Lang, C. T. and O'Leary, J. T.

1996 "Understanding vacation destination choice through travel motivation and activities". Journal of

Vacation Marketing, 2(2): 109-122.

Mowforth, M. and Munt, I.

2003 Tourism and sustainability. London: Routledge.

MTUR.

2008 Chamada Pública MTUR n. 001/2008: Apoio às iniciativas de turismo de base comunitária.

Brasília: Ministério do Turismo.

MTUR.

2010 Dinâmica e diversidade do turismo de base comunitária: Desafio para a formulação de política

pública. Brasília: Ministério do Turismo.

MTUR e FGV.

2010 Turismo no Brasil 2011-2014. Brasília, Distrito Federal.

Nunkoo, R. y Ramkissoon, H.

2011 "Developing a community support model for tourism". Annals of Tourism Research, 38(3): 964-988.

Palhares, G.

2002 Transportes turísticos. São Paulo: Aleph.

Pearce, D.

2003 Geografia do turismo: fluxos e regiões no mercado de viagens. São Paulo: Aleph.

Pretty, J.

1995 The many interpretations of participation. Focus, 16: 4-5.

Rivera Mateos, M. y Rodríguez García, L.

2012 Turismo responsable, sostenibilidad y desarrollo local comunitario. Córdoba: Cátedra Intercultural

y Universidad de Córdoba.

Ruiz, E., Hernández, M., Coca, A., Cantero, P. y Del Campo, A.

2008 "Turismo comunitario en Ecuador. Comprendiendo el community-based tourism desde la comunidad".

Revista de Turismo y Patrimonio Cultural, 6(3): 399-418.

Ruschmann, D.

2002 Turismo e Planejamento Sustentável. Campinas: Papirus.

Saarinen J.

2006 "Traditions of Sustainability in Tourism Studies". Annals of Tourism Research, 33(4): 1121-1140. 
Sansolo, D. e Bursztyn, I.

2009 "Turismo de base comunitária: potencialidade no espaço rural brasileiro". In Bartholo, R., Sansolo,

D. G e Bursztyn, I. (Orgs.), Turismo de base comunitária: Diversidade de olhares e experiências brasileiras (pp. 142-161). Rio de Janeiro: Letra e Imagem.

Serrano-Barquín, R., Cruz Jiménez, G., Arguello Zepeda, F., Osorio García, M. e Sánchez Barreto, R. F. 2011 "La complejidad, expresión de nuestro tiempo: el turismo desde los sistemas complejos". Revista de Cultura y Turismo, 1:4-24.

Sharpley, R.

2000 "Tourism and sustainable development: exploring the theoretical divide". Journal of Sustainable Tourism, 8(1): 1-19.

Swarbrooke, J.

2000 Turismo Sustentável: conceitos e impacto ambiental. São Paulo: Aleph.

Tosun, C.

2000 "Limits to community participation in the tourism development process in developing countries".

Tourism Management, 21: 613-633.

Tosun, C.

2006 "Expected nature of community participation in tourism development". Tourism Management, 27: 493-504.

TUCUM

2008. Rede Cearense de Turismo Comunitário. Presentation held at the II International

Seminar on Sustainable Tourism. Fortaleza.

UNCTAD/WTO.

2005 Módulo de Treinamento para o Sucesso do Turismo Baseado na Comunidade: TBC no Âmbito do

PRPE - Programa de Redução da pobreza através da Exportação. Genebra: Internacional Trade Center. UNWTO.

2014 UNWTO Tourism Highlights. Madrid: UNWTO.

Vera, J. F., López Palomeque, F., Marchena, M. J. y Antón, S.

1997 Análisis territorial del turismo. Barcelona: Ariel.

Vignati, F.

2008 Gestão de destinos turísticos: como atrair pessoas para pólos, cidades e países. Rio de Janeiro: Senac. WB.

2012 Global economic prospects 2012: Uncertainties and vulnerabilities. Washington: World Bank.

WTO.

2004 Indicators of sustainable development for tourism destinations. Madrid: WTO.

WTO.

2010 World Tourism Barometer. Madrid: WTO.

WTO.

2013 World Tourism Barometer. Madrid: WTO.

WWF.

2003 Manual de Ecoturismo de Base Comunitária: ferramentas para um planejamento responsável.

Brasília: WWF Brasil. 